\title{
EFEKTIVITAS PENGGUNAAN MEDIA EDMODO PADA PEMBELAJARAN MATEMATIKA EKONOMI TERHADAP KOMUNIKASI MATEMATIS
}

\author{
Anton Nasrullah ${ }^{1}$, Ende $^{2}$, Suryadi $^{3}$ \\ ${ }^{1,2}$ Perguruan Tinggi Bina Bangsa, ${ }^{3}$ STKIP Banten \\ 1 antonnasrullah24@yahoo.com, ${ }^{3}$ suryadiyadi426@yahoo.com
}

\begin{abstract}
ABSTRAK
Seiring perkembangan teknologi baik secara langsung maupun tidak langsung dapat merubah seseorang dalam berkomunikasi, bersosialisasi dan belajar, hal ini merupakan sebuah tantangan untuk para pendidik agar dapat menggunakan teknologi secara optimal dan dapat memudahkan interaksi dengan peserta didik dalam proses belajar mengajar baik didalam kelas maupun diluar kelas sehingga indikator dalam satauan acara perkulihan dan silabus dapat tercapai. Penelitian bertujuan: 1) untuk mengetahui apakah pembelajaran matematika ekonomi yang menggunakan Edmodo (eksperimen) lebih baik dibandingkan dengan pembelajaran tanpa menggunakan Edmodo (konvensional) terhadap komunikasi matematis; 2) untuk mengetahui apakah mahasiswa yang belajar dengan menggunakan Edmodo bersikap positif terhadap pembelajaran matematika ekonomi. Penelitian kuantitatif dengan metode quasi-experiment, desain penelitian yang digunakan adalah nonequivalent control group design: memberikan dua perlakuan yang berbeda terhadap dua kelompok yaitu kelas eksperimen (Edmodo) dan kelas kontrol (konvensional). Teknik pengumpulan dan analisis data kuantitatif dengan menggunakan uji normalitas, uji homogenitas, uji kesamaan dua rata-rata, dan uji t. Hasil penelitian adalah; 1) pembelajaran matematika ekonomi yang menggunakan Edmodo (eksperimen) lebih baik dibandingkan dengan pembelajaran tanpa menggunakan Edmodo (konvensional) terhadap komunikasi matematis; 2) mahasiswa yang belajar dengan menggunakan Edmodo bersikap positif terhadap pembelajaran matematika ekonomi.
\end{abstract}

Kata Kunci : Edmodo, efektifitas, komunikasi matematika, sikap.

\begin{abstract}
As the development of technologies either directly or indirectly, can change a person in communicating, socializing and learning, this is a challenge for educators in order to optimally use technology and can facilitate interactions with learners in the learning process of teaching both in class and out of class so that the indicators in units of of events lectures and syllabus can be achieved. The goal of the research is: 1) to know whether learning economic mathematics using Edmodo (experimentation) is better than of learning without using Edmodo (conventional); 2) to find out if students learn using Edmodo positive towards the learning of mathematical economics. quantitative research methods with quasi-experiment, the research design used was a nonequivalent control group design: give two different treatment of two groups, the experimental classes (Edmodo) and control classes (conventional). Techniques of collection and analysis of quantitative data by using test of normality, test its homogeneity, test the equality of two averages, and test results of the study are; 1) learning economic mathematics using Edmodo (experimentation) is better than of learning without using Edmodo (conventional); 2) students studying using Edmodo positive towards the learning of mathematical economics.
\end{abstract}

Keywords: Edmodo, effectiveness, mathematics communication, attitude. 


\section{A. PENDAHULUAN}

Perkembangan Information and Communication Technology (ICT) menuntut dunia pendidikan terus mengalami peningkatan mutu terutama penyesuaian penggunaan ICT dalam proses pembelajaran (Sampurno, Maulidiyah, \& Puspitaningrum, 2015), namun kenyataanya adalah sepertiga dari 1000 pengajar jarang yang menggunakan ICT sebagai media pembelajaran (Marjal, 2014).

Seiring perkembangan teknologi baik secara langsung maupun tidak langsung dapat merubah seseorang dalam berkomunikasi, bersosialisasi dan belajar, hal ini merupakan sebuah tantangan untuk para pendidik agar dapat menggunakan teknologi secara optimal dan dapat memudahkan interaksi dengan peserta didik dalam proses belajar mengajar baik secara tatap muka langsung mapun secara tidak langsung (online) sehingga indikator dalam satuan acara perkuliahan (SAP) dan silabus dapat tercapai.

Setiap subsesi perkuliahan banyak indikator ketercapaian dalam SAP dan silabus yang harus dicapai, maka upaya yang dilakukan adalah membuat modul dalam bentuk cetak. Namun mahasiswa memiliki kecenderungan menghilangkan modul dalam bentuk cetak, ketinggalan, rusak dan lain-lain. Untuk mengatasi hal ini, yang dilakukan dalam perkembangan ICT adalah mentrasformasikan modul pembelajaran dalam bentuk cetak menjadi non cetak (online) yaitu dengan menggunakan aplikasi Edmodo sebagai alat penunjang proses belajar mengajar.

Edmodo merupakan website jejaring sosial yang mirip dengan facebook yang digunakan untuk proses pembelajaran (Gruber, 2008). Edmodo sering disebut sebagai facebook-nya pendidik karena Edmodo diperuntukkan bagi pendidik, peserta didik dan orang tua. Hasil penelitian (Al-said, 2015) menjukan bahwa dalam proses pembelajaran menggunakan Edmodo secara umum dapat menghemat waktu. Penggunakan Edmodo memiliki banyak tantangan dan potensi yang bagus dalam pembelajaran (Al-Kathiri, 2015).

Edmodo merupakan salah satu jenis teknologi komunikasi dan informasi dalam bentuk website jejaring social yang mirip dengan facebook yang digunakan untuk proses pembelajaran sehingga mempermudah proses pembelajaran baik pendidik, peserta didik dan orang tua yang dapat memuat berbagai media yang berupa gambar, animasi, teks, dan suara (Gruber, 2008). Hal ini merupakan langkah awal penggunaan semua indera peseta didik untuk mudah mengingat pembelajaran, karena menghubungkan dengan penguasaan materi dalam proses belajar mengajar. Hasil penelitian (Colin and Malcolm, 2002) dalam proses belajar mengajar mengatakan bahwa tingkat retensi peserta didik akan mencapai: membaca $20 \%$, mendengar $30 \%$, melihat $40 \%$, melakukan $60 \%$, dan melihat, mengucapkan, mendengar serta melakukan $90 \%$.

Inti proses pengajaran adalah kegiatan belajar peseta didik dalam mencapai suatu tujuan pembelajaran. Tercapai atau tidaknya tujuan pembelajaran dapat dilihat dari hasil belajar yang diperoleh peseta didik, setelah proses pembelajaran selesai, salah satunya adalah 
mencapai komunikasi secara matematis. Komunikasi matematis dipengaruhi oleh kemampuan peseta didik dan tinggi rendahnya atau efektifitas tidaknya proses pembelajaran.

Penggunaan Edmodo mempunyai peranan penting dalam proses pembelajaran yaitu sebagai media pembelajaran matematika (Imam, 2013). Hasil penelitian yang dilakukan oleh (Al-said, 2015) menyatakan bahwa proses pembelajaran Edmodo dapat menciptakan aktifitas belajar yang menarik, inovatif dan efektif. Pembelajaran. Edmodo dapat diakses melalui web dan smartphone (Windows Phone, iOS, Android, dll) secara online yang didalamnya terdapat ruang virtual untuk pendidik dan peserta didik untuk berbagi dan mendiskusikan ide, dan file (teks, gambar, audio, dan video) (Al-said, 2015).

Penanaman konsep dapat mudah diterima bagi peseta didik apabila proses belajar melibatkan peseta didik secara optimal dalam kegiatan pembelajaran. (Colin dan Malcolm, 2002) mengemukakan bahwa aset terbaik peseta didik adalah kemampuan kolektif peseta didik untuk belajar cepat dan beradaptasi secara cerdas terhadap situasi yang tidak bisa diramalkan. Edmodo merupakan lingkungan pembelajaran online aman dan bebas dari iklan, game dan gangguan lainnya yang dapat digunakan untuk berkomunikasi antara pendidik dengan peserta didik baik pelajaran, pekerjaan rumah, dan berkolaborasi dengan teman sekelas (Shams-abadi, Ahmadi, \& Mehrdad, 2015).

Edmodo dapat digunakan sebagai platform komunikasi pembelajaran untuk mendukung pembelajaran peserta didik di tingkat individu, kelompok dan tingkat seluruh kelas, baik di dalam maupun di luar kelas, yang dapat digunakan di seluruh formal dan informal pengaturan belajar, memungkinkan peserta didik untuk berkolaborasi, berkomunikasi, menyerahkan tugas dan meng-upload dan download file, dan pendidik untuk berbagi catatan kuliah dengan peserta didik, terhubung ke situs web yang berguna, upload dan download belajar referensi bagi siswa, membuat quiz online, berita notifikasi dan agenda acara (Kong \& Song, 2014).

Hasil penelitian menunjukkan bahwa alat digital seperti Edmodo dapat memberikan ruang kerja yang benar-benar kolaboratif bagi mahasiswa luar dinding kelas, mempromosikan berbagai jalan untuk belajar konstruktif, dan mendorong agar lebih tinggi keterampilan yang diperlukan berpikir dalam masyarakat abad ke-21 (Mcclain, 2015), hal ini dapat menstimulus dan membekali mahasiswa dalam kompentensi komunikasi secara matematis dimasa mendatang

UNESCO (Kariadinata, 2006) menyatakan bahwa penggunaan ICT dalam pembelajaran memiki tiga tujuan yaitu;1) untuk membangun knowledge based society habits seperti kemampuan pemecahan masalah, kemampuan berkomunikasi, kemampuan mencari/mengelola informasi, mengubah informasi tersebut menjadi pengetahuan baru dan menginformasikan kepada orang lain; 2) untuk mengembangkan kemampuan menggunakan ICT; 3) untuk meningkatkan efektifitas dan efisiensi pembelajaran. 
Kemampuan komunikasi matematis merupakan elemen penting dalam pengajaran dan pembelajaran matematika (Pugalee, Bissell, Lock, \& Douville, 2003), kemampuan komunikasi matematis adalah kemampuan siswa dalam menggambar, membuat ekspresi matematika, atau menulis jawaban mereka dengan bahasa mereka sendiri, terkait dengan berbagai situasi atau matematika ide yang disajikan dalam bentuk gambar, diagram, grafik, simbol, barang cerita, atau model matematika (Tandililing, 2011).

Peneliti dari Texas A \& M Universitas di Amerika Serikat menyatakan bahwa peserta didik akan hanya mempertahankan 20\% dari apa yang mereka dengar, 30\% dari apa yang mereka lihat dan 50\% dari apa yang mereka lihat dan dengar (Ezrailson et al., 2006). Namun, ketika pendidik fokus pada interaksi dan komunikasi di dalam kelas, peserta didik akan mempertahankan 90\% dari apa yang mereka katakan dan lakukan, karena mereka terlibat dalam diskusi (Ezrailson et al., 2006).

National Council of Teachers of Mathematics' (NCTM, 2000): peserta didik harus terlibat dalam percakapan di mana ide-ide matematis dieksplorasi dari beberapa perspektif. Komunikasi merupakan pengiriman dan penerimaan berita antara dua orang atau lebih yang diungkapkan dalam bentuk lisan dan tulisan secara sitematis (pendidik dengan peserta didik/ peserta didik dengan peserta didik) secara tepat sehingga dipahami (Dogoriti et al, 2014). Salah satu alternatif pembelajaran matematika adalah dengan menggunakan komputer secara daring (online) melalui Edmodo sebagai alat penunjang dalam proses belajar mengajar matematika terhadap komunikasi matematis.

Kemampuan komunikasi matematis mahasiswa pada pembelajaran matematika menurut (Anderson and Krathwhol, 2001) taksonomi Bloom adalah: Interpreting, Exemplifying, Classifying, Summarizing, Inferring, Comparing, Explaining. Tujuan kegiatan penelitian adalah: 1) untuk mengetahui apakah pembelajaran matematika ekonomi yang menggunakan Edmodo (eksperimen) lebih baik dibandingkan dengan pembelajaran tanpa menggunakan Edmodo (konvensional) terhadap komunikasi matematis; 2) untuk mengetahui apakah mahasiswa yang belajar dengan menggunakan Edmodo bersikap positif terhadap pembelajaran matematika ekonomi.

Salah satu alternatif pembelajaran yang memungkinkan dapat mengembangkan kemampuan komunikasi matematika adalah pembelajaran dengan aplikasi Edmodo sebagai alat penunjang dalam proses belajar mengajar matematika ekonomi dengan menggunakan komputer secara daring (online), berdasarkan uraian diatas berkeinginan untuk melakukan penelitian tentang efektivitas penggunaan Edmodo pada pembelajaran matematika ekonomi terhadap komunikasi matematis. 


\section{B. METODE PENELITIAN}

Penelitian ini marupakan penelitian kuantitatif dengan menggunakan metode quasiexperiment desain yang digunakan adalah nonequivalent kontrol group: memberikan dua perlakuan yang berbeda terhadap dua kelompok yaitu kelas eksperimen (Edmodo) dan kelas kontrol (konvensional).

Penelitian tentang efektivitas penggunaan media Edmodo terhadap komunikasi matematis pada pembelajaran matematika ekonomi dilaksanakan salah satu perguruan tinggi di Banten pada bulan April sampai Mei 2016, populasi merupakan keseluruhan subjek penelitian (Creswell, 2016), populasi yang digunakan dalam penelitian adalah seluruh mahasiswa semester genap semester dua jurusan akuntansi tahun akademik 2015/2016.

Sampel adalah bagian dari populasi yang dapat dianggap mewakili dan mencerminkan keadaan populasi (Sukmadinata, 2005), semua kelas semester dua mempunyai kesempatan yang sama untuk dipilih menjadi tempat penelitian, untuk keperluan penelitian, pengambilan sampel diambil dua kelas secara tidak acak yaitu; kelas A dan B jurusan akuntansi semester genap tahun akademik 2015/2016. Bahan dan alat dalam penelitian adalah komputer, LCD, koneksi internet, dan sumber bahan ajar.

Definisi operasional variabel penelitian; 1) Edmodo merupakan salah satu jenis teknologi komunikasi dan informasi dalam bentuk website jejaring social yang mirip dengan facebook yang digunakan untuk proses pembelajaran, sehingga mempermudah proses pembelajaran baik pendidik, peserta didik dan orang tua yang dapat memuat berbagai media yang berupa gambar, animasi, teks, dan suara (Gruber, 2008) ; 2) komunikasi matematis adalah pengiriman dan penerimaan berita antara dua orang atau lebih yang diungkapkan dalam bentuk lisan dan tulisan (pendidik dengan peserta didik, peserta didik dengan peserta didik).

Teknik pengumpulan dan analisis data analisis data yang digunakan dalam penelitian adalah sebagai berikut:

\section{Data Kuantitatif (Tes Komunikasi Matematika)}

Data kuantitatif dalam penelitian adalah nilai diperoleh dari mahasiswa kelompok eksperimen maupun kelompok kontrol yaitu: tes awal (pre-test) dan tes akhir (post-test). Statistik yang dipergunakan adalah: uji rata-rata (uji-t) dipergunakan untuk melihat kemampuan komunikasi mahasiswa antara mahasiswa yang memperoleh pembelajaran dengan menggunakan Edmodo dengan mahasiswa yang tidak memperoleh pembelajaran dengan menggunakan Edmodo. Analisis data kuantitatif dilakukan dengan langkah-langkah sebagai berikut:

\section{Uji Rata-Rata Tes Awal (Pre-Test)}

Tes awal (pre-test) sebelum dilakukan, soal tes komunikasi matematika di uji validitas, reliabilitas, indeks kesukaran, daya pembeda, setelah itu dilakukan tes awal (pre-test) kemudian teknik pengumpulan dan analisis data kuantitatif dengan menggunakan uji homogenitas, uji 
kesamaan dua rata-rata yaitu untuk mengetahui kemampuan awal matematika apakah ada perbedaan kelas eksperimen dan kelas kontrol sebelum ada perlakuan.

3. Uji Rata-Rata Tes Akhir (Post-Test)

Tes post-test dilakukan setelah mendapatkan perlakuan baik kelas eksperimen maupun kelas kontrol teknik analisis data hasil post-test yang dilakukan sama dengan teknik analisis data hasil pre-test yaitu uji perbedaan rata-rata melalui uji t untuk mengetahui apakah apakah pembelajaran matematika ekonomi yang menggunakan Edmodo (eksperimen) lebih baik dibandingkan dengan pembelajaran tanpa menggunakan Edmodo (konvensional) terhadap komunikasi matematis.

\section{Data Kulitatif (Skala Sikap)}

Angket merupakan isian skala sikap berisi respon mahasiswa terhadap pembelajaran dengan menggunakan Edmodo dengan acuan indikator skala sikap dan komunikasi matematika, langkah-langkah yang digunakan adalah sebagai berikut:

5. Mengubah Data Kualitatif Menjadi Skala Kuantitatif (Skala Likert)

Instrumen skala sikap menggunakan skala Likert dan hanya diberikan kepada kelompok eksperimen dan bertujuan untuk mengetahui sikap mahasiswa terhadap model pembelajaran Edmodo, didalam instrumen skala sikap ada 3 (tiga) kelompok yaitu; 1) sikap mahasiswa terhadap pembelajaran menggunakan Edmodo; 2) sikap mahasiswa terhadap soalsoal yang diterima selama proses penelitian berlangsung; 3) nilai gabungan rata-rata sikap mahasiswa terhadap pembelajaran menggunakan Edmodo.

6. Menghitung rata-rata skor Skala Sikap

Menurut Ruseffendi (2005) sebelum melakukan penafsiran, terlebih dahulu data yang diperoleh dihitung nilai rata-ratanya. Setiap kategori: jika $\geq 3$ maka dapat dipandang sikap mahasiswa positif terhadap model pembelajaran dengan menggunakan Edmodo, Jika < 3 maka dapat dipandang sikap mahasiswa negatif terhadap model pembelajaran dengan menggunakan Edmodo. Teknik Analisis data skala sikap dilakukan dengan mencari: rata-rata sikap untuk dijadikan standar penentuan sikap didalam item sikap yang diolah untuk masing-masing kelompok.

\section{HASIL DAN PEMBAHASAN}

Berdasarkan hasil pengujian tes awal (pre-test) kelas eksperimen maupun kelas kontrol adalah: kedua kelas tersebut bersifat homogen, berdistribusi normal, kemampuan awal kedua kelas tersebut tidak berbeda secara signifikan. Hasil tes awal (pre-test) sangat membantu untuk melihat perkembangan komunikasi matematika setelah diberikan perlakuan pembelajaran, setelah melakukan pembelajaran baik kelas ekperimen maupun kelas kontol selanjutnya adalah melakukan tes akhir (post-test). Hasil rekapitulasi skor kelas kelas ekperimen dan kontol adalah sebagai berikut: 
Tabel 1.

Skor Pre-Test dan Post-Test

\begin{tabular}{clrrrr}
\hline \multirow{2}{*}{ Kelas } & & $\begin{array}{r}\text { Pre-Test } \\
(\mathrm{n}=35)\end{array}$ & $\begin{array}{r}\text { Post-Test } \\
(\mathrm{n}=35)\end{array}$ & $\mathrm{T}$ & $\mathrm{F}$ \\
\hline \multirow{2}{*}{ Eksperimen } & $\bar{x}$ & 17.87 & 59.86 & -3.180 & \multirow{2}{*}{1.88} \\
& $\mathrm{SD}$ & 6.97 & 13.31 & & \\
\multirow{2}{*}{ Kontrol } & $\bar{x}$ & 22.91 & 41.63 & 5.63 & \multirow{2}{*}{0.14} \\
& $\mathrm{SD}$ & 6.27 & 13.79 & & \\
\hline
\end{tabular}

Berdasarkan Tabel 1 terlihat bahwa nilai signifikansi $t_{\text {hitung }}=5.63$ lebih besar dari pada $\mathrm{t}_{\text {tabel }}=2.00$, maka dapat disimpulkan bahwa terdapat perbedaan yang signifikan rata-rata skor post-test antara kelompok eksperimen dengan kelompok kontrol.

Hasil analisis pada Tabel 1 menunjukan bahwa terdapat perbedaan yang signifikan ratarata skor postes antara kelompok eksperimen, artinya pembelajaran matematika ekonomi yang menggunakan Edmodo (eksperimen) lebih baik dibandingkan dengan pembelajaran tanpa menggunakan Edmodo (konvensional) terhadap komunikasi matematis, hal ini sejalan dengan hasil penelitian (Kong \& Song, 2014) bahwa media Edmodo dapat secara efektif dalam pengembangan pedagogis dengan dasar teoritis pembelajaran.

Penggunaan Edmodo dapat membantu mengembangkan kompetensi: kemapuan manggunakan media, kolaborasi virtual dan pengelolaan kognitif yang sejalan dengan hasil penelitian (Gómez, Magreñán, \& Orcos, 2015). Hal ini dilakukan dalam memanfaatkan ICT dari sumber-sumber yang ada disekitar: wifi, smartphone, komputer, laptop, dan warnet seperti yang diungkapkan oleh (Shams-abadi, Ahmadi, \& Mehrdad, 2015).

Belajar dengan menggunakan Edmodo (daring) efektif dalam pembelajaran matematika karena memberikan pengalaman yang baik yaitu memudahkan mahasiswa dalam mengerjakan quiz online yang dapat dilakukan dari mana saja dan kapan saja (Kongchan, 2012), mudah memperoleh materi ajar dalam berbagi video, file, folder (Ali, 2015), komunikasi secara matematik (pendidik dengan peserta didik/ peserta didik dengan peserta didik) selama proses belajar mengajar dan mendapatkan umpan balik yang dapat membantu penilaian (Dogoriti., et al, 2014) sehingga dosen dapat merekapitulasi nilai secara otomatis.Hasil rekapitulasi hasil skala sikap dapat dilihat pada Tabel 2.

Berdasarkan hasil rekapitulasi data skala sikap pada Tabel 2 dalam aspek pembelajaran matematika yaitu sikap mahasiswa terhadap pembelajaran dengan Edmodo menunjukan sikap yang positif karena dapat menumbuhkan semangat dalam belajar dan meningkatkan komunikasi dan interaktif, hal ini sejalan dengan pendapat (Nee, 2014). 
Tabel 2.

Hasil Data Skala Sikap

\begin{tabular}{|c|c|c|c|c|}
\hline No & $\begin{array}{l}\text { Aspek Pembelajaran } \\
\text { Matematika }\end{array}$ & Indikator & Rata-Rata & Keterangan \\
\hline \multirow{4}{*}{1.} & \multirow{4}{*}{$\begin{array}{l}\text { Sikap mahasiswa tehadap } \\
\text { pembelajaran dengan } \\
\text { Edmodo }\end{array}$} & $\begin{array}{l}\text { Kemudahan dalam } \\
\text { penggunaan Edmodo }\end{array}$ & 3.70 & Positif \\
\hline & & $\begin{array}{l}\text { Kesulitan dalam } \\
\text { penggunaan Edmodo }\end{array}$ & 3.65 & Positif \\
\hline & & $\begin{array}{l}\text { Keaktifan dalam } \\
\text { penggunaan Edmodo }\end{array}$ & 3.67 & Positif \\
\hline & & $\begin{array}{l}\text { Rata-rata sikap mahasiswa } \\
\text { tehadap pembelajaran } \\
\text { dengan Edmodo }\end{array}$ & 3.67 & Positif \\
\hline 2. & $\begin{array}{l}\text { Sikap mahasiswa terhadap } \\
\text { soal-soal yang mereka } \\
\text { peroleh dalam } \\
\text { pembelajaran dengan } \\
\text { Edmodo }\end{array}$ & $\begin{array}{l}\text { Kesukaan dan manfaat } \\
\text { contoh soal, soal latihan } \\
\text { dan tugas. }\end{array}$ & 3.73 & Positif \\
\hline 3. & Keseluruhan & $\begin{array}{l}\text { Jumlah rata-rata aspek } \\
\text { pembelajaran matematika }\end{array}$ & 3.68 & Postif \\
\hline
\end{tabular}

Sikap mahasiswa terhadap soal-soal yang diperoleh selama proses belajar mengajar menjukan sikap yang positif karena didalam aplikasi Edmodo memfasilitasi proses belajar mengajar dalam mengerjakan soal-soal yang diberikan dan dapat mendiskusikan contoh soal dan latihan soal dengan (pendidik dengan peserta didik) atau (peserta didik dengan peserta didik) secara daring sehingga komunikasi lebih efektif, dan menghemat waktu, hal ini sejalan dengan pendapat (Al-said, K. M, 2015) menyatakan bahwa Edmodo dapat memfasilitasi dan meningkatkan komunikasi dan efeisien dalam waktu pada saat diluar kelas (daring).

\section{KESIMPULAN}

1) Pembelajaran matematika ekonomi yang menggunakan Edmodo (eksperimen) lebih baik dibandingkan dengan pembelajaran tanpa menggunakan Edmodo (konvensional) terhadap komunikasi matematis.

2) Mahasiswa yang belajar dengan menggunakan Edmodo bersikap positif terhadap pembelajaran matematika ekonomi.

\section{E. REKOMENDASI}

Berdasarkan hasil penelitian dan skala sikap yang menunjukan positif dari peserta didik (mahasiswa) dalam proses belajar mengajar dalam matakuliah matematika ekonomi, maka implementasi pembelajaran menggunakan Edmodo dapat digunakan sebagai alat penunjang pembelajaran di kampus maupun di sekolah agar dapat lebih efektif dan efisien dalam waktu 
baik didalam kelas maupun diluar kelas secara daring (online) sehingga hasil pembelajaran lebih optimal.

\section{F. UCAPAN TERIMAKASIH}

Peneliti mengucapkan terima kasih kepada DRPM dan Perguruan Tinggi Bina Bangsa karena telah memberikan dukungan finansial. Peneliti mengucapkan terima kasih kepada pihak yang telah membantu dalam kegiatan penelitian yang dilakukan khususnya Dr. Ade Sumiardi yang berkontribusi dalam diskusi atau pengolah data yang terkait langsung dengan penelitian/penulisan.

\section{G. REFERENSI}

Anderson, L.W., Krathwohl, D.R. (Eds). (2001). A Thaxonomy for Learning, Teaching, and Assessing: A Revision of Bloom's Taxonomy of Educational Objectives. New York: Addison Wesley Longman.

Ali, Z. (2015). A Case Study of Tertiary Students Experiences Using Edmodo in Language Learning. International Journal of Language Education and Applied Linguistics (IJLEAL). 02, 39-48.

Al-kathiri F. (2015). Beyond the Classroom Walls : Edmodo in Saudi Secondary School EFL Instruction, Attitudes and Challenges. Journal Canadian Center of Science and Edocation. 8(1), 189-204.

Al-said, K. M. (2015). Student's Perceptions of Edmodo and Mobile Learning and their Real Barriers towards them. The Turkish online Jurnal of Educationnal Technology (TOJET). 14 (2), 167-180.

Colin, R., Malcolm N. (2002). Accelerated Learning for The 21st Century Cara Belajar Cepat Abad XXI. Jakarta: Nuansa.

Creswell, J. W. (2010). Research Design Pendekatan Kualitatif, Kuantitatif dan Mixed. Yogyakarta: Pustaka Pelajar

Dogoriti, E., Pange, J. (2014). Instructional Design for a "Social" Classroom: Edmodo and Twitter in the Foreign Language Classroom. International Conference on Information Communication Technologies in Education (IICTE), Proceedings, University of Loannina, Greece, 154-165

Ezrailson, C., Kamon, T., Loving, C. C., and McIntyre, P. M. (2006). Teaching through interactive engagement: Communication is experience. School Science and Mathematics, 106(7), 278-279.

Gómez, A., Magreñán, Á. A., \& Orcos, L. (2015). UX of social network Edmodo in undergraduate engineering students. International Journal of Artificial Intelligence and Interactive Multimedia. 3(4), 31-36. http://doi.org/10.9781/ijimai.2015.346

Gruber, Frank. (2008). Edmodo: Microblogging for Education. [Online] Tersedia: http://www.somewhatfrank.com/2008/03/Edmodo-microblo.html. Diakses 12 Desember 2015

Imam, F. (2013). Efektifitas E-learning Melalui Edmodo terhadap Hasil Belajar Peserta Didik pada Materi Statistika SMA, FKIP PGRI Semarang; Semarang 
Kariadinata, Rahayu. (2006). Aplikasi Multimedia Interaktif dalam Pembelajaran Matematika sebagai Upaya Mengembangkan Kemampuan Berfikir Matematika Tingkat Tinggi Siswa SMA.Disertasi PPS UPI: Tidak diterbitkan.

Kong, S. C., \& Song, Y. (2014). The Impact of a Principle-based Pedagogical Design on Inquiry-based Learning in a Seamless Learning Environment in Hong Kong. Educational Technology \& Society, 17(2), 127-141.

Kongchan, C. (2012). How a Non-Digital Native Teacher Makes Use of Edmodo. In 5th Intenational Conference ICT for Language Learning, Florence, Italy

Marjal, J. (2014). Studi Penggunaan Jejaring Sosial Edmodo sebagai Media E-Learning oleh Dosen Senior yang tidak terbiasa Bekerja dengan Komputer, Jurnal Edumatica, 4 (1)

Mcclain, C. (2015). Characterization Personified: Using Edmodo to Strengthen Student Interaction with Literature Alan Brown, School Computer Technologies Journal, Vol $18,1-19$.

NCTM. (2000). Principles and Standards for School Mathematics. Reston, VA: author

Nee, C. K. (2014). The Effect of Educational Networking on Students' Performance in Biology. International Journal on Integrating Technology in Education, 3(1), 21-41. http://doi.org/10.5121/ijite.2014.3102

Pugalee, D. K., Bissell, B., Lock, C., \& Douville, P. (2003). The Treatment of Mathematical Communication in Mainstream Algebra Texts, (September). The Mathematics Education into the $21^{\text {st }}$ Century Project Proccedings of the international conference, University of North Carolina - Charlotte, NC 28262, United States of America, 238241.

Ruseffendi, E. T. (2005). Dasar-Dasar Penelitian Pendidikan dan Bidang Non Eksakta Lainnya, Bandung: Tarsito.

Sampurno, P. J., Maulidiyah, R., \& Puspitaningrum, H. Z, (2015). Implementasi Kurikulum 2013 : MOODLE (Modular Object Oriented Dynamic Learning Environment) dalam Pembelajaran Fisika melalui Lembar Kerja Siswa pada Materi Optik di SMA. Jurnal Fisika Indonesia No: 55, Volume XIX.

Shams-abadi, B. B., Ahmadi, S. D., \&Mehrdad, A.G., (2015).The Effect of Edmodo on EFL Learner's Writing Performance. International Journal of Educational Investigations. 2(2), 88-97.

Sukmadinata, NS. (2005). Metode Penelitian Pendidikan, Bandung: Remaja Rosdakarya.

Tandililing, E. (2011). The Enhancement of Mathematical Communication and Self-Regulated Learning of Senior High School Students Through PQ4R Strategy Accompanied by Refutation Text Reading, International Seminar and the Fourth National Conference on Mathematics Education, Yogyakarta State University, P - 86, 978-979.

Widodo, A. (2006). Taksonomi Bloom dan Pengembangan Butir Soal. Buletin Puspendik. $3(2), 18-29$. 